\title{
THE ROLE OF ARCHITECTURAL DESIGN IN SUPPORTING THE REQUIREMENTS OF USERS WITH INTELLECTUAL DISABILITY
}

\author{
Ghada Hafez Awaad Hafez ${ }^{* 1}$, Essam El-din Badran, ${ }^{2}$ and Faisal Mahmoud \\ Abulazm ${ }^{2}$ \\ ${ }^{1}$ Engineering administration, Suez Canal Authority, Ismailia, Egypt. \\ ${ }^{2}$ Architecture and Urban Planning Department, Faculty of engineering Suez Canal \\ University, Ismailia, Egypt. \\ *Corresponding Author E-mail: eng.ghada.hafez@gmail.com
}

\section{ABSTRACT:}

Architecture is mainly concerned with establishing an appropriate environment that enables individuals to live in comfortable environment that guarantees his dignity. The problem of people with intellectual disability is in movement from one place to another and lack of training and skills with the surrounding environment as he depends in most cases on individuals or assistive devices, and to be able to deal in a more flexible way in public and private spaces like government buildings, markets, recreational and service buildings, and other buildings that may be frequented by, it is required to achieve a architectural technical standards related to services located in those places in terms of their positions, dimensions and required spaces. Design considerations are divided into physical problems (mental behavioral - mobility - hearing - visual), and psychological needs (intimate atmosphere containment - privacy - simplicity and clarity - ease of movement - colors). Egypt sought through years of time to provide support and requirements that work on the care and rehabilitation of the disabled and allocated so many agencies and institutions that serve those requirements such as youth and the labor force and the Ministry of Education, health and housing. A study was conducted on the current situation of a building that deals directly with individuals with intellectual disability (Suez Canal Authority capacity center) and evaluated that data and knowing the strengths and weaknesses points based on what has been extracted from standard design considerations. These considerations could be taken into account as guidelines for the decision makers through setting and enforcing the legislation.

KEY WORDS: Intellectual Disability, Psychological Needs, Physical Problems, Behavioral Problems, Mental Problems.

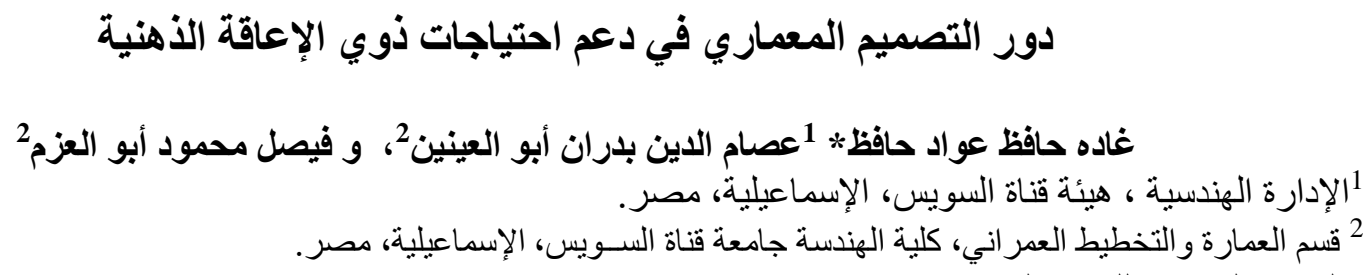

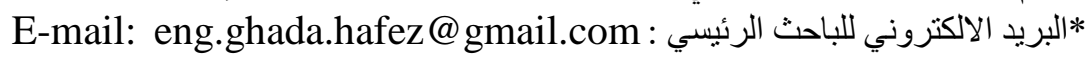

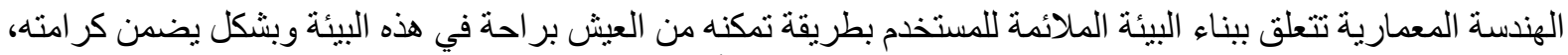
وتتمثل مشكله ذوى الإعاقة الذهنية في الحركة والتتقل من مكان لأخر وقله التدريب و المهار ات مع البئئة المحيطة إذ يعتمد 
في معظم الحالات على من حوله من أفر اد أو أدو ات مساعدة، ولكي يتمكن من التعامل بطريقة أكثر مرونة بالأماكن

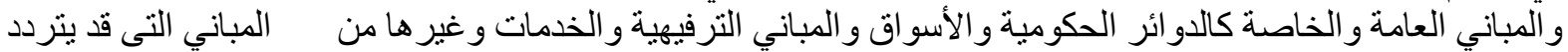

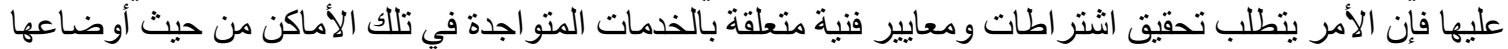

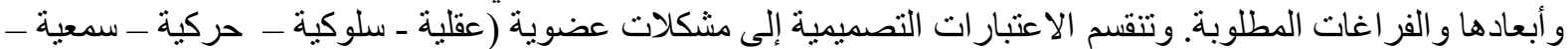

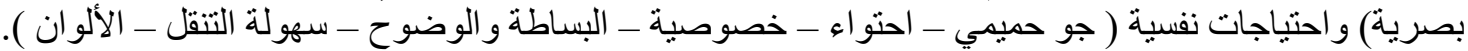

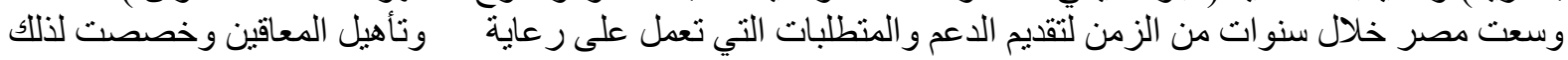

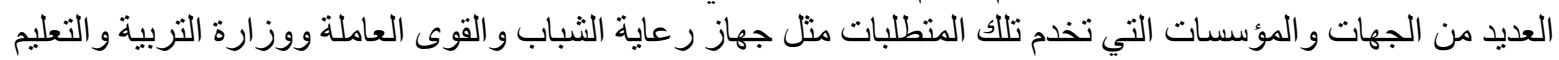

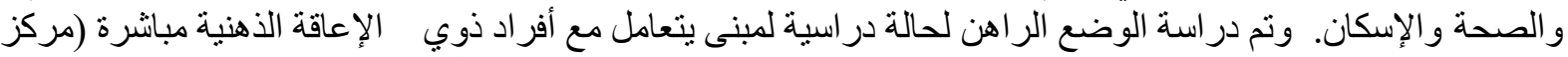

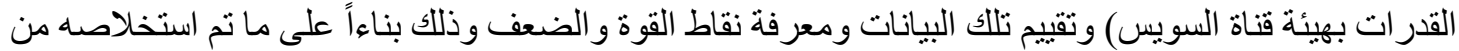

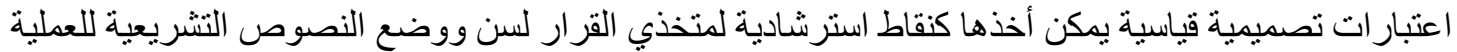
التصميمية لمباني المعاقين ذهنياً.

الكلمات المفتاحية : الإعاقة الذهنية ، مشكلات عضوية ، احتياجات نفسية ، المشكلات السلوكية، المشكلات العقلية.

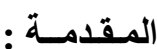

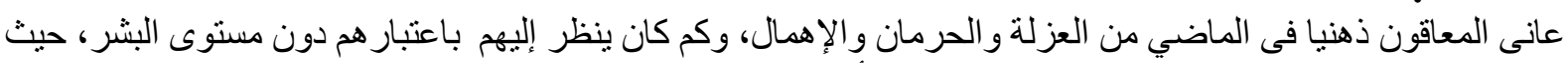

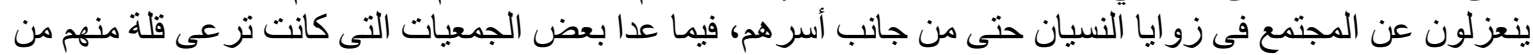

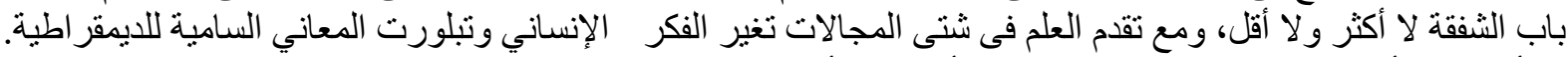

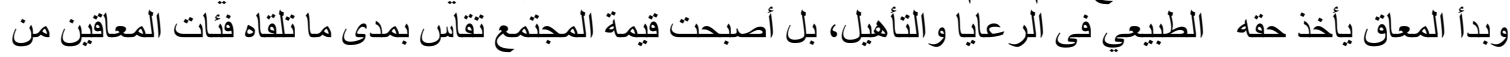

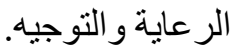

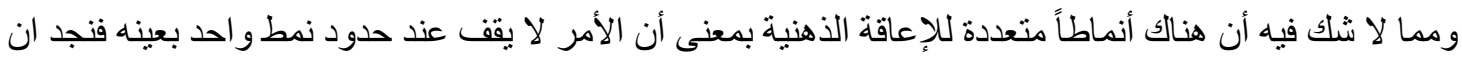

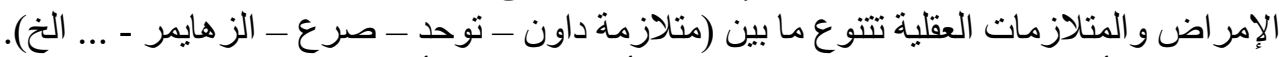

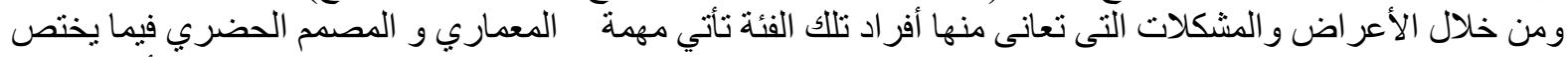

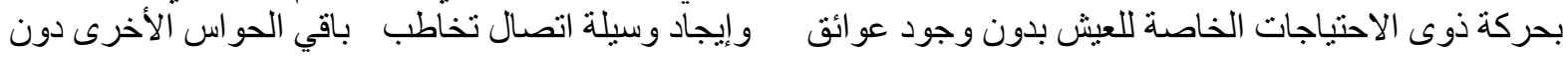

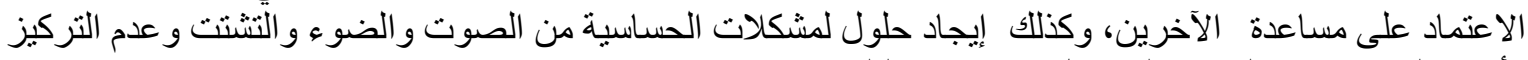

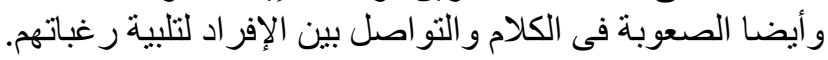

المشكلة البحثية:

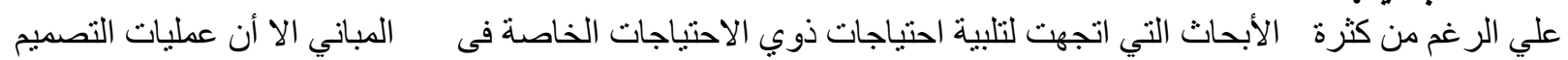

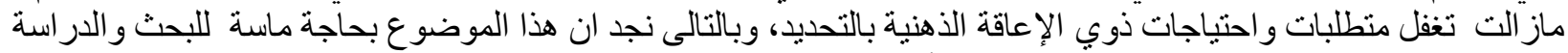

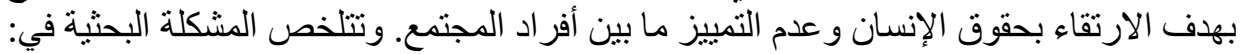

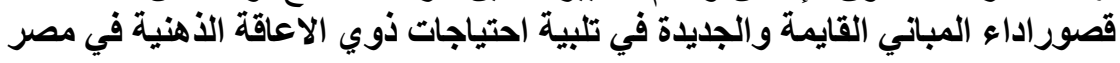

1- الإعاقة طبقاً لتعريف منظمة الصحة العالمية هي: "مصطلح يغطي العجز، والقيود على العي النشاط، ومقيدات المشاركة.

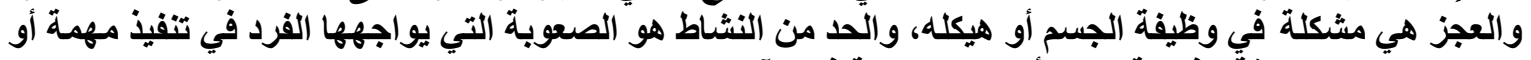
عمل، وتختّف الإعاقة الذهنية عن الأمراض العقلية في الآتي [1]:

\begin{tabular}{|c|c|c|}
\hline 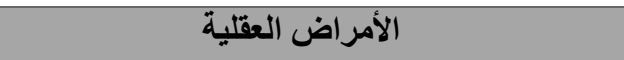 & الإعاقة الذهنية & \\
\hline 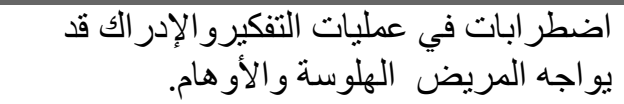 & الأداء الوظيفي العقلية الإدراكية والمعية محدودة بسبب مستوى & 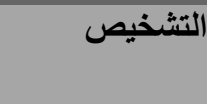 \\
\hline قد تلكون دائمة أو مؤقتة أو متكررة على فترات & تلكساليب الإصلابة به مختلى الحياه مهما خضع الثخص & الت التاريخ المرضي \\
\hline يمكن أن تحدث في أى وقت من العمر. & غالبا ما يحدث قبل سن 18 سنه. & 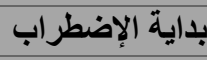 \\
\hline 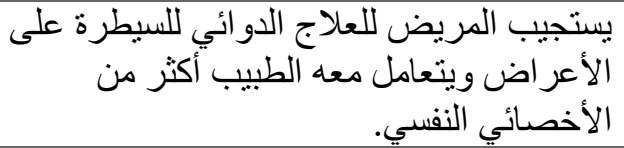 & النفعلاج الدو ائي لا يمكنه استعادة القدائي النفسي أكثر من الدكترفية & 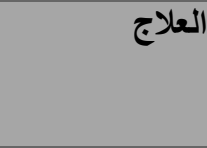 \\
\hline
\end{tabular}


ويوجد أربعة جوانب من السمات الرئيسية للإعاقة [2]:

\begin{tabular}{|c|c|}
\hline الجانب الشخصي & الجاتب الذهني \\
\hline 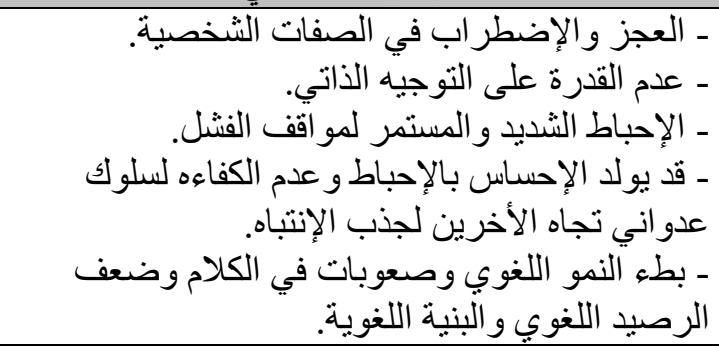 & 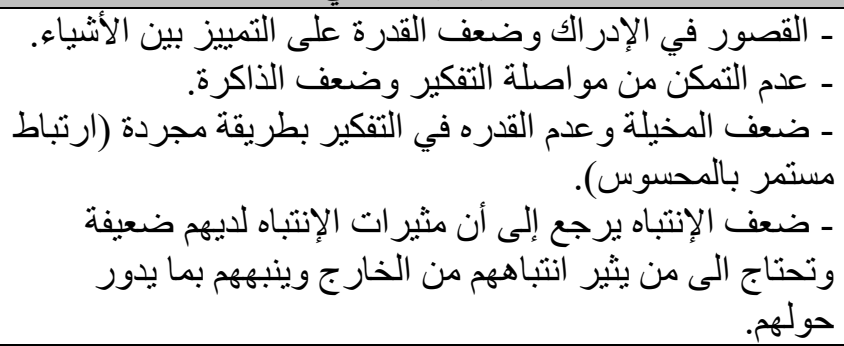 \\
\hline الجاتب الاجتماعي & الجانب الحركي \\
\hline 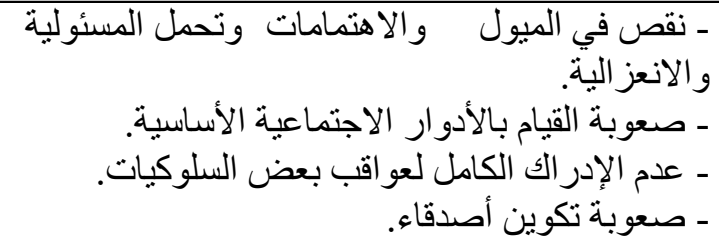 & 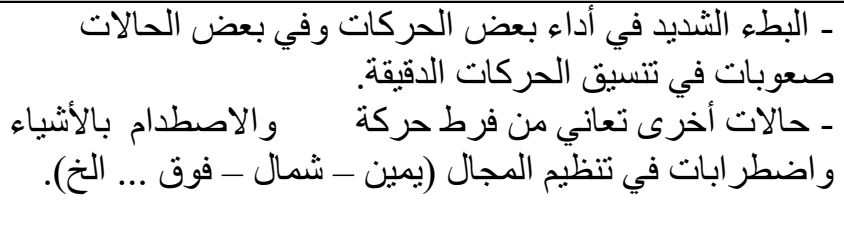 \\
\hline
\end{tabular}

وتثمل الاعاقة الذهنية الحالات التالية :

$$
\text { * * التخلف العقلي. }
$$

\begin{tabular}{|c|c|c|c|c|c|}
\hline ضمور المخ & الزهايمر & ونقص الإنتباه & التوحد & التخلف العقلي & \\
\hline 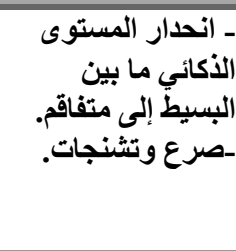 & 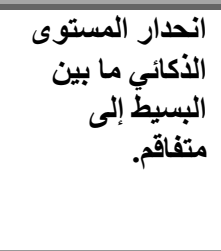 & & 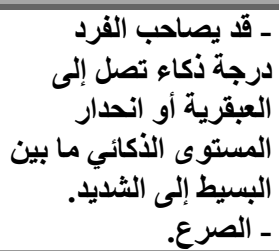 & الثا بين البسبط إلى الذكائي & وحالة المخ العقلية \\
\hline - & - & ـ ـ ـ تشتئ الانتباه & 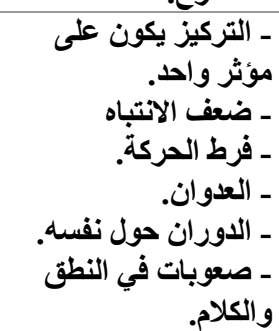 & 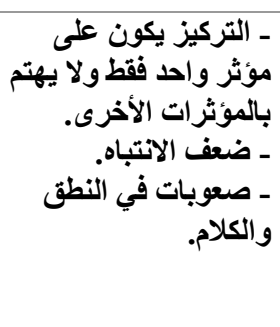 & المشاكل السلوكية \\
\hline 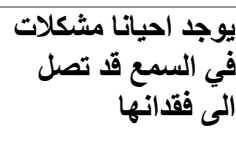 & ضعف الحالة & الأصطواتات من & 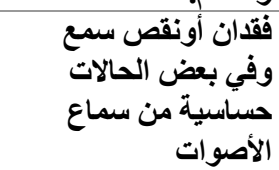 & & الحالة السمعية \\
\hline - الضوء في اسية منض. & ضعف الحالة & 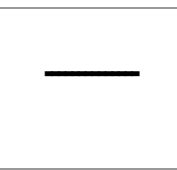 & بعدم القدرة الحاتي تعاني من & بعض الحالات. من الضوء في & الحالة البصرية \\
\hline 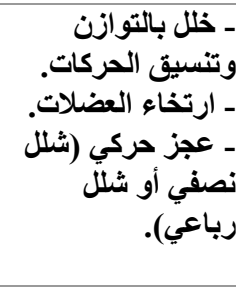 & 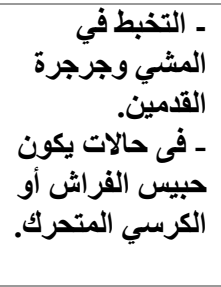 & والالات فرط تعانية & 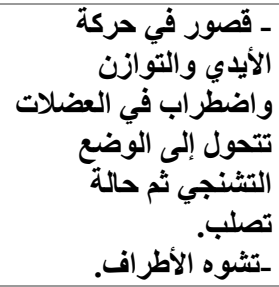 & ـ ـ قدر قامة حركي. & الحالة الحركية \\
\hline
\end{tabular}

2- وتتمثل مشكلات المعاقين ذهنياً في الآتي: 


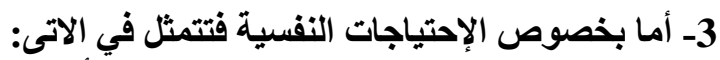

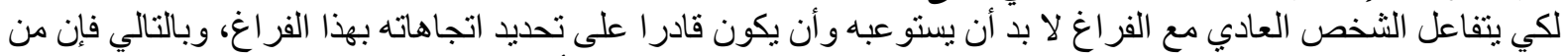

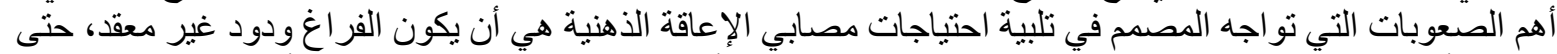

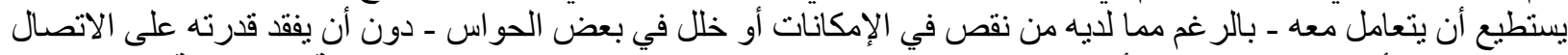

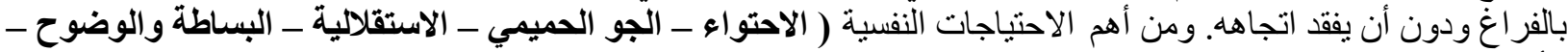

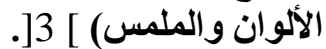
4 - مراحل تظور خدمات الصحة العقلية بداية من مرحلة ما قبل الميلاد حنى وقتنا هذا على النحو الاتي:

\begin{tabular}{|c|c|}
\hline نبذة عن المرحلة & الحقبة الزمنية \\
\hline 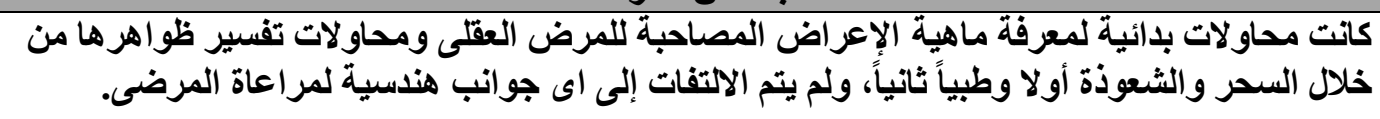 & مرحلة ما قبلّ \\
\hline 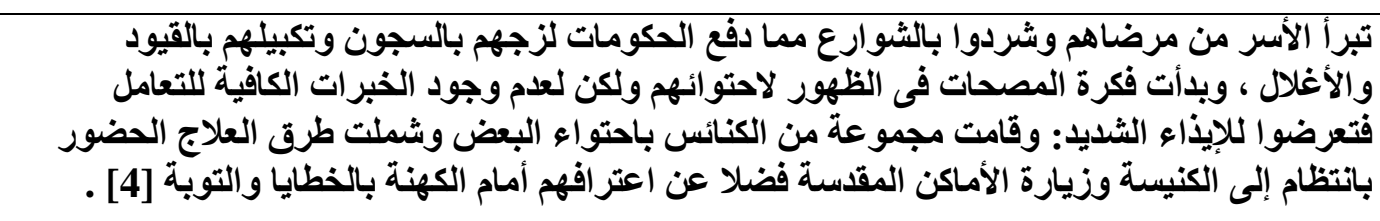 & التاسى القرن عشر \\
\hline 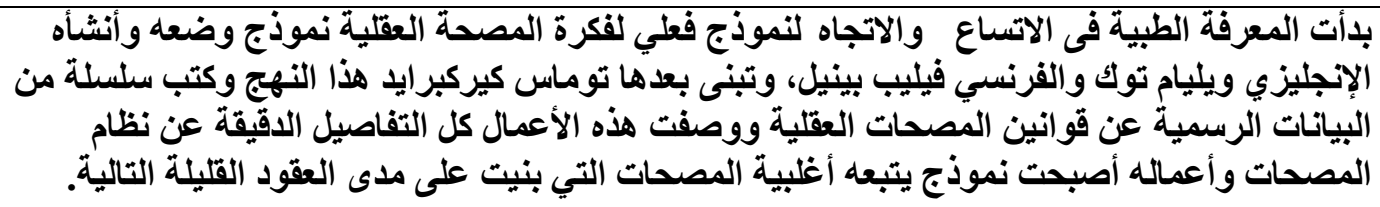 & العشّرين القرن \\
\hline 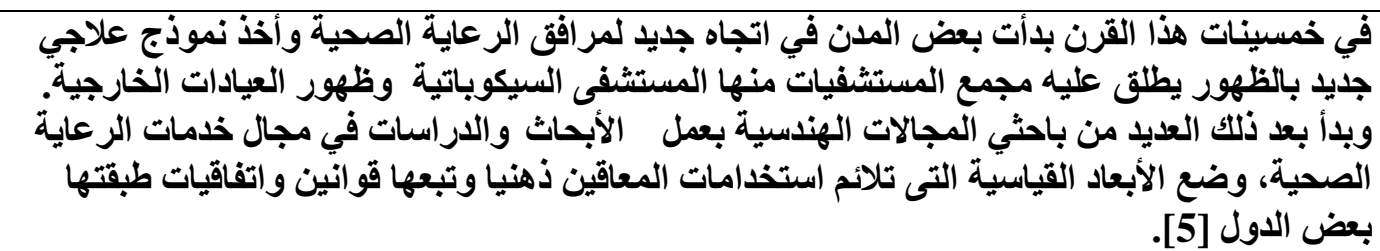 & العشرينة القرن \\
\hline
\end{tabular}

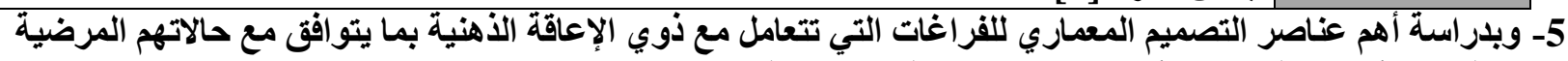
عضوية كانت أو نفسية ومدى تأثير ذلك على العملية التصميمية تبين الآتي:

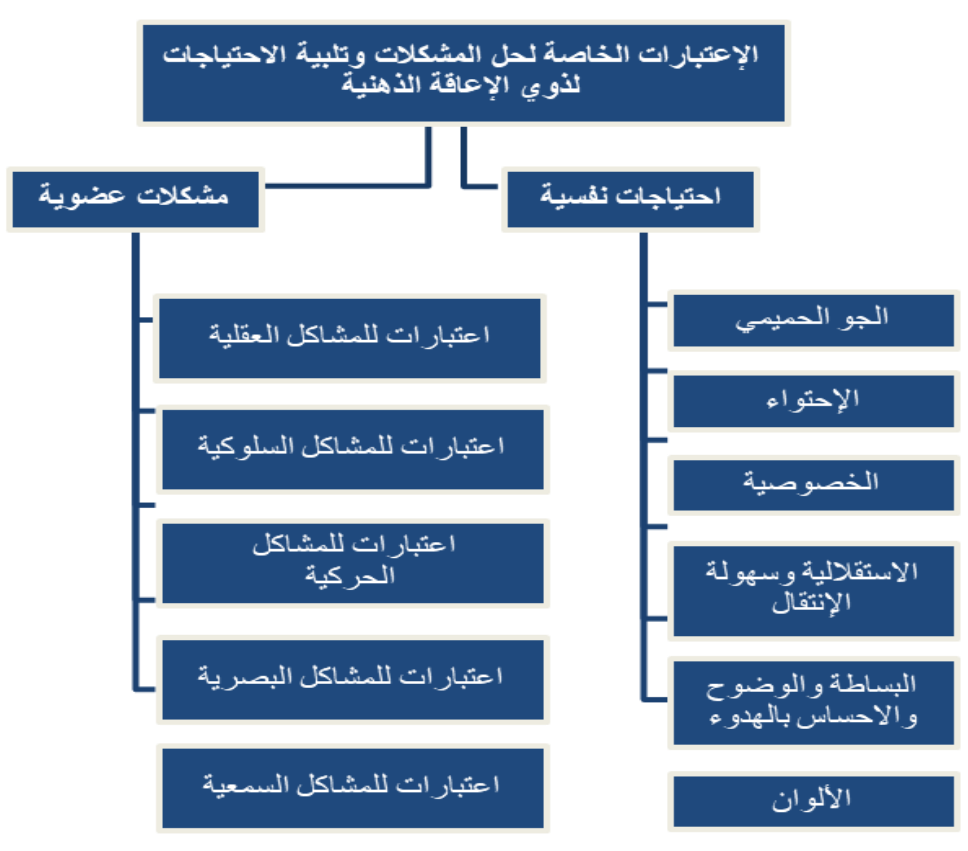




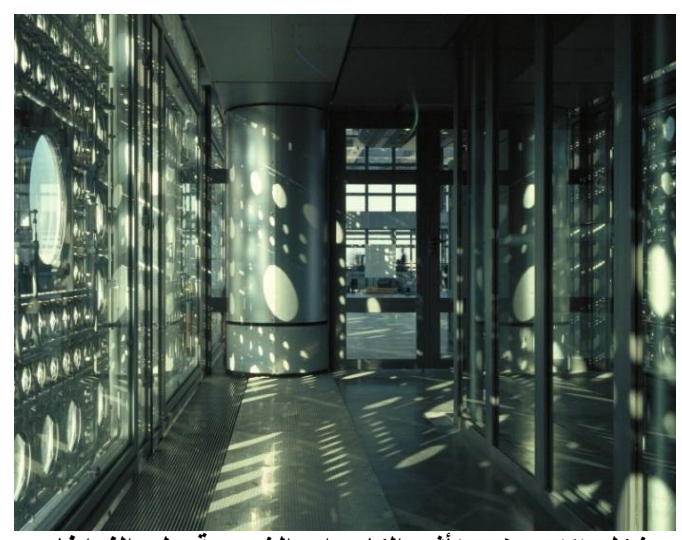

شكل (1) يوضح تأثير الكاسرات الثمسية على الفراغات الاخلية مما يسبب الانزعاج البصري.

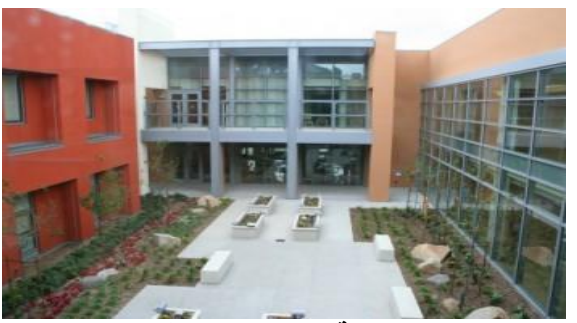

شكل (2) يبين درجة الانغلاق الفراغي لفناء داخلى بمستثفى New Edgemoor بالولايات المتحدة

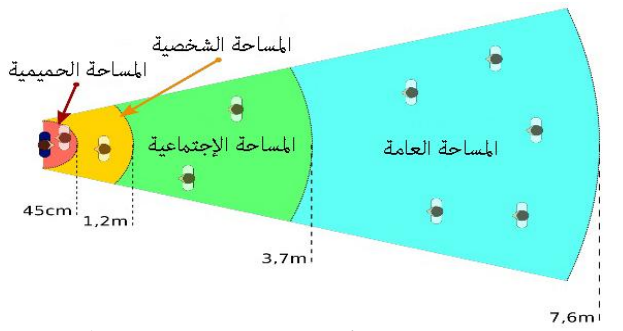

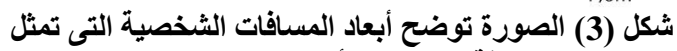
علاقة الإنسان بالأشخاص من حوله

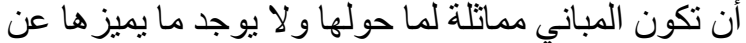
بقية المباني في المنطقة المحيطة .

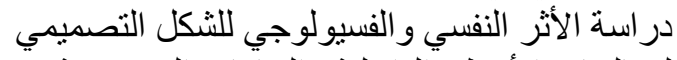

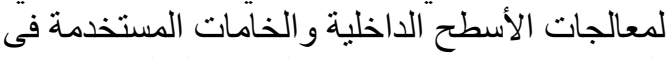
التكسيات خاصة في منشات الصحة العقلية. تجنب المعالجات التصميمية التي ينتج عنها ظلال كثيفة، لما يسببه ذلك من عدم وضوح الرؤية.

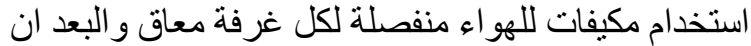

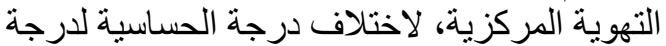

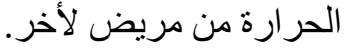

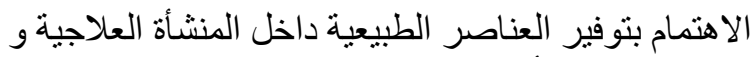
التي تتمثل في الأفنية و الحدائق الخلفية و الداخلية و اختيار الموّاقع المناسبة لها. مر اعاة أن اللعب يعتبر الماملانلا مهم ا في تعليم و تعديل السلوك. - ماع.

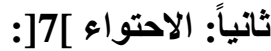

نسب الفراغ تؤثر بشكل كبير على مشاعر مستخدميه

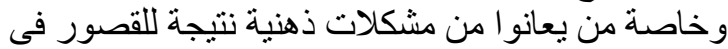

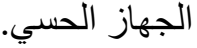
الانغلاق الفر اغي لله دور في التحديد البصري للفر اغي ويقلل

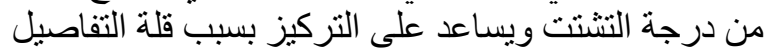

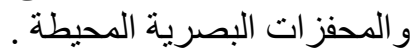

ثالثاً: الخصوصية [8]: • محاولة البعد عن الفر اغات المفتوحة لافتقادها للخصوصية.

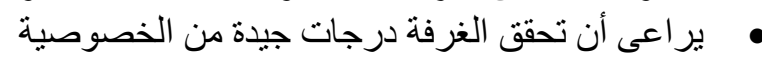

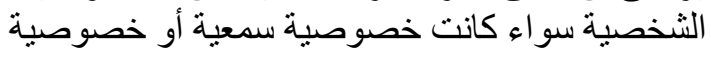
بصرية.

\footnotetext{
رابعاً: الاستقلالية وسـهولة الانتقال [19]:

إعطاء شخصية مميزة لكل مكان مختلف عن الأخر بصرئاً. عدم إعطاء المستخدم العديد من الاختيار ات خلاءل ملاء مسار الحركة.

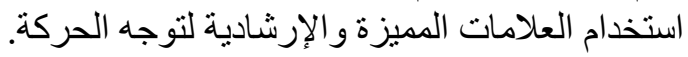

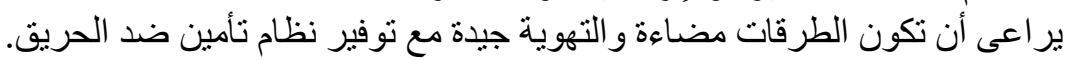
أن يكون عرض الممر كافيا بحث يسمح بمرور مريضين فئن فئ اتجاهين متعاكسين. يجب عدم وجود درجة أو درجتين فقط عند تغبير المنسوب لاحتمال عدم رؤيتها والتعثربها.
} 


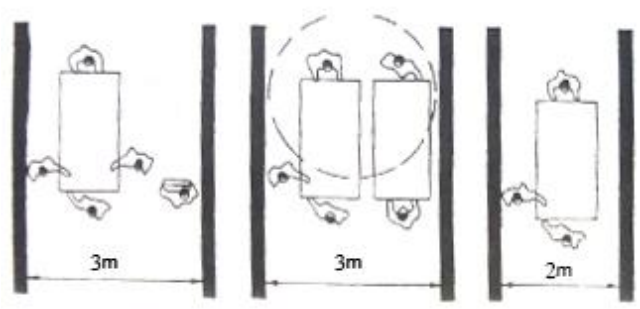

شكل (4) يوضح الحركة داخل الطرقات وأبعادها

• مكن استخدام لونين متناقضين لكلا من النائمة و القائمة.

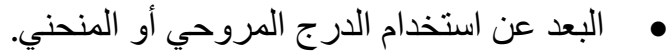
• توفير مقعد يمكن طيه داخل المصعد وذللك للأفَر اد الذين الذين

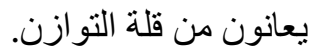

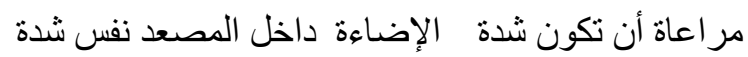

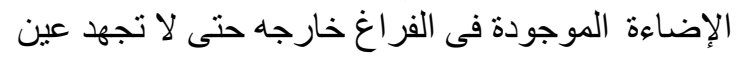

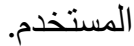

خامساً: البساطة والوضوح والإحساس بالهاوء ]10]:

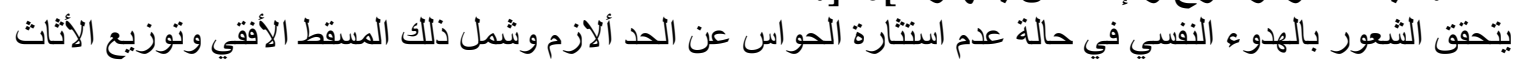

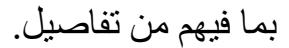
الفراغ قد يكون له شكل محدد وو اضيح يسهل التعرف عليه، وقد يكون غير محدد الثكل متعدد الأسطح و الاتجاهات

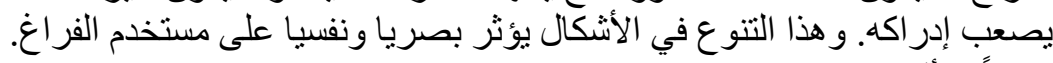

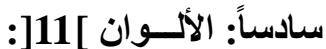
هؤنر الألو ان علي ادارك الإنسان الإنسان للحجم بشكل مختلف عما هو في الحقيقة.

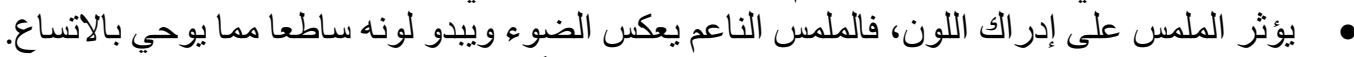
تجنب الخداع البصري في الألوان و الأشكال إذ يسبب تونر آ للمعوق ذهنيا ويربكه.

5

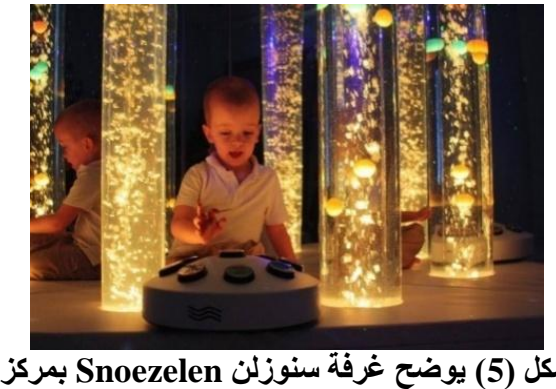
العلاج والتدخل بلدبي.

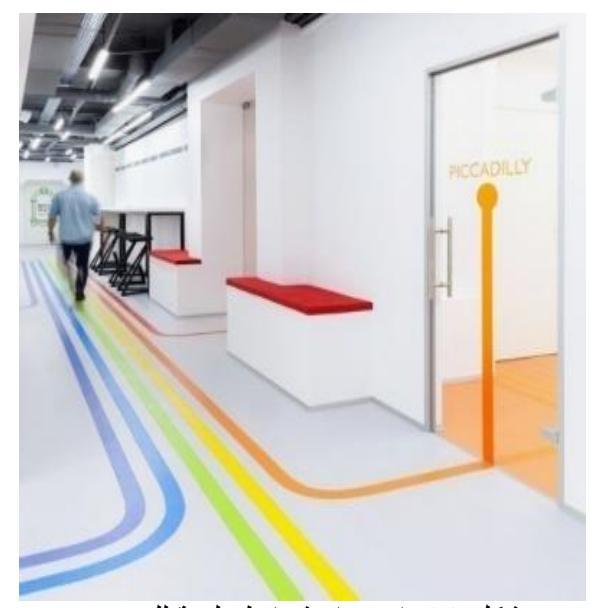

شكل (6) استخدام شر ائط ملونة للتوجيه.
أولاً: المشكلات العقلية [12]:

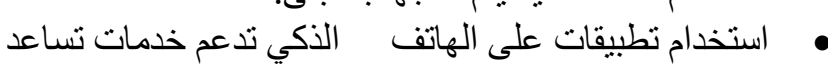

مرضى المشكلات العقلية.

ثانياً: المشكـلات السلوكية [13]

يتم تحديد ارتفاع السقف تبعاً لنو عية النشاط داخل الفر اغ. من الممكن توفير نظام اشعاعي يمر تحت أرضية التهاعة الحمام مما يثركها جافة طيلة الوقت. استخدام الأرضيات تفاعلية مع حركة الإنسان.

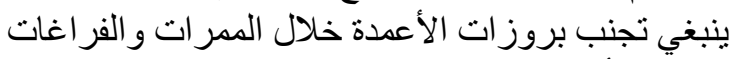

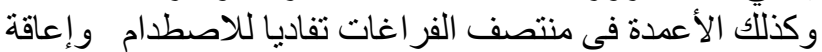
الحركة.

الحماية من مخار ج التدفئة و الكهرباء و الأسلاك ومفاتيح الإنارة.

البعد عن وجود أى زو ايا بالحائط أو الفرش الداخلى سو اء حادة

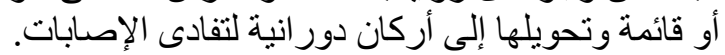

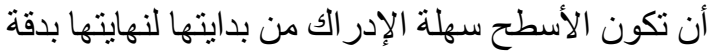

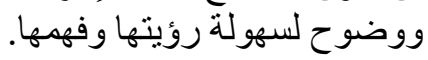

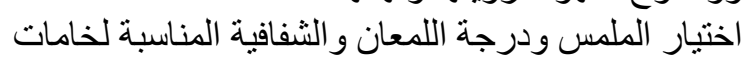
التكسية لتتلاءم مع الإضاءة الطبيعية و الصناعية. معالجة الأسطح الخشنة حيث يمكن أن يسقط على حو افها. يجب تجنب التعددية الوظيفية لقطع الأثاث.

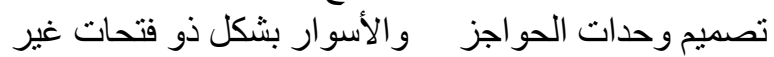

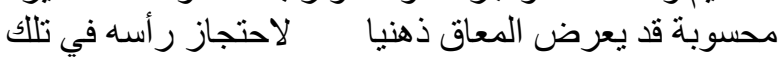
الفتحات 

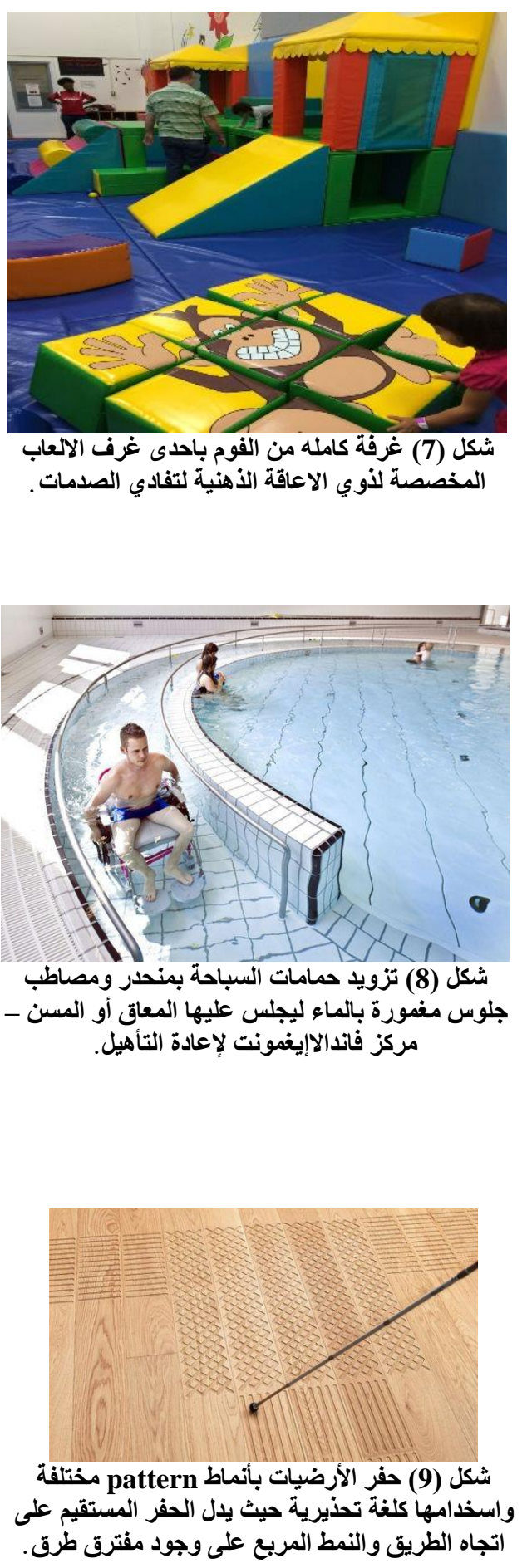

• بفضل الأثاث أن يكون مثبتا في الأرض أو الحائط. • • • • • • • • •

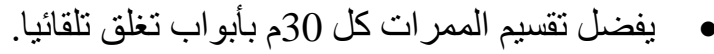

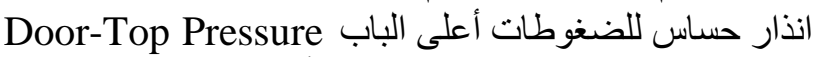

Sensitive Alarm

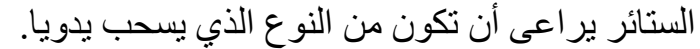

يجب أن يكون رأس الدش ثابت غير النير متحرك لتجنب سوء

الاستخدام.

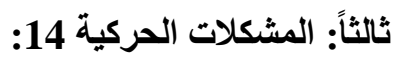

• اعى خلو ممر ات المشاه من أى عائق مثل فتحات الصرف.

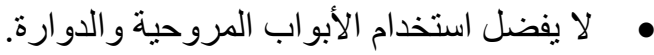

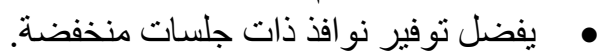

لايزيد ميل المنحدر ات عن 1:20 مع مع نوفير صدفة أفقية إذا زاد

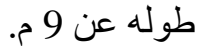

عند التصميم الانشائي للأسقف يجب الأخذ في الاعتبار معدات الرفع (الأوناش) التي تنقل مصابي الحركة من مكان لأخر.

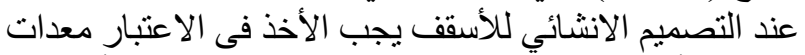

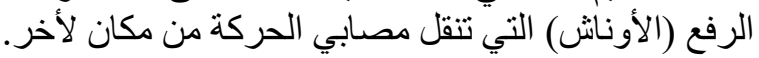

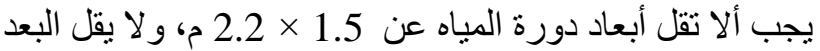
بين الباب و المرحاض عن 1.5 1.5. توفير أماكن للمعاقين فى قاعات المحاضر آلرات و والمؤتمر ات

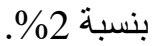

رابعاً: المشكلات البصرية 15:

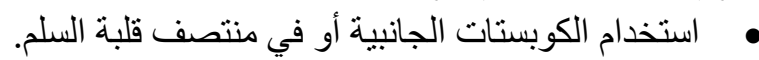

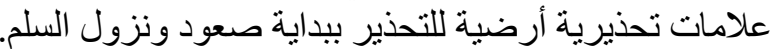
تزويد ارشادات المرور الضوئية للمشاة بوسائل مسمو عة لئل

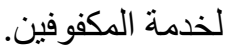

خامساً: المشكلات السمعيـة 16:

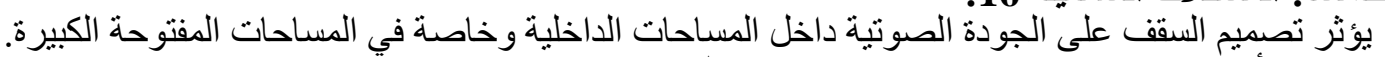

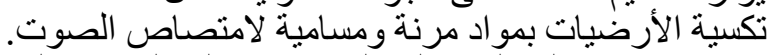

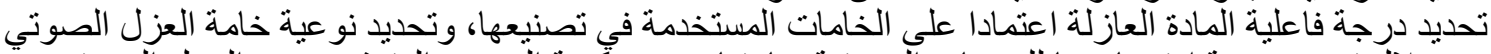

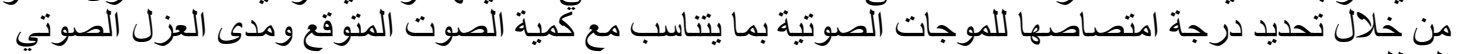

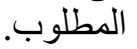


6- مثال تطبيقي : مركز القدرات لذوي الاحتياجات الخاصة بهيئة قناة السويس

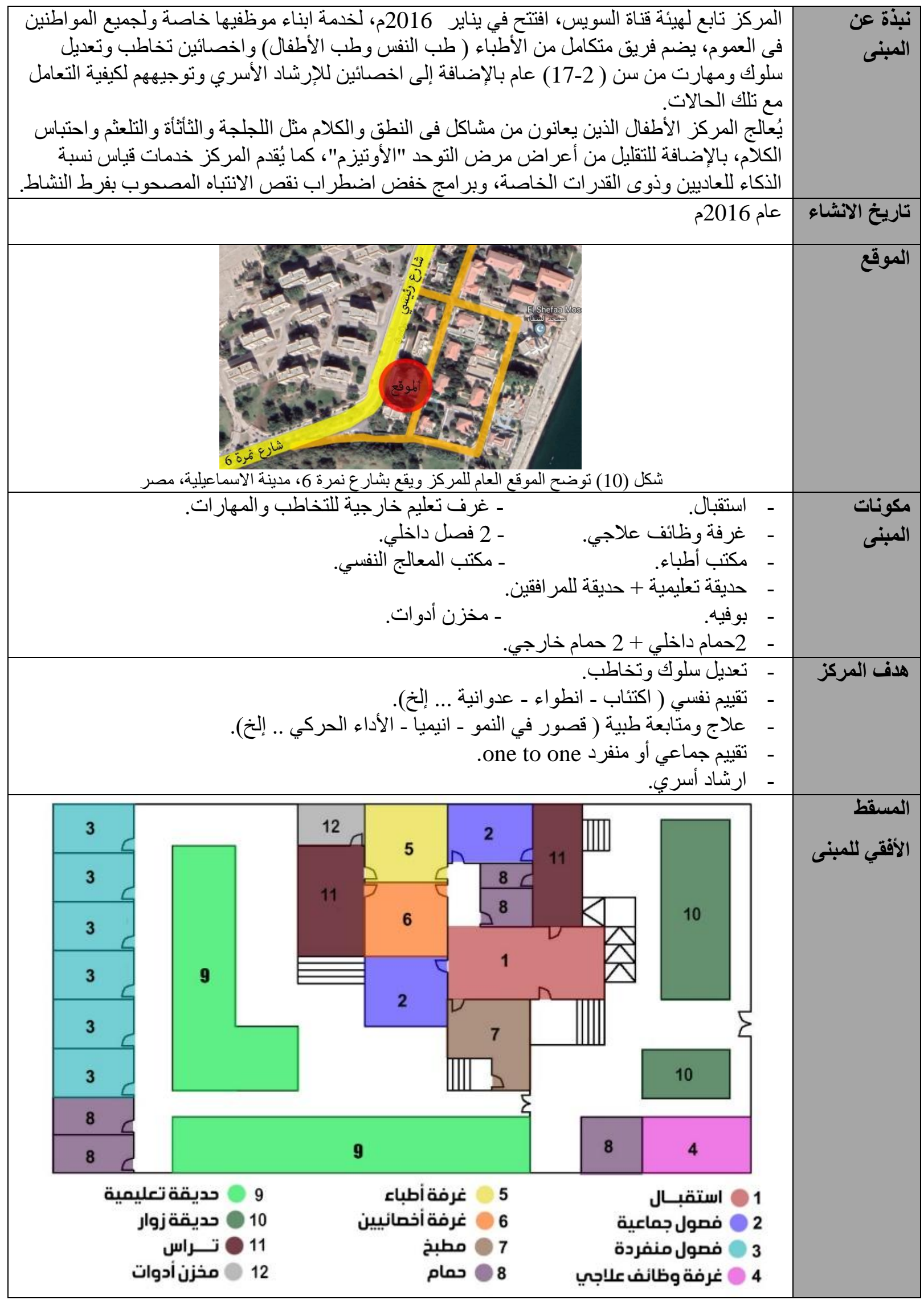




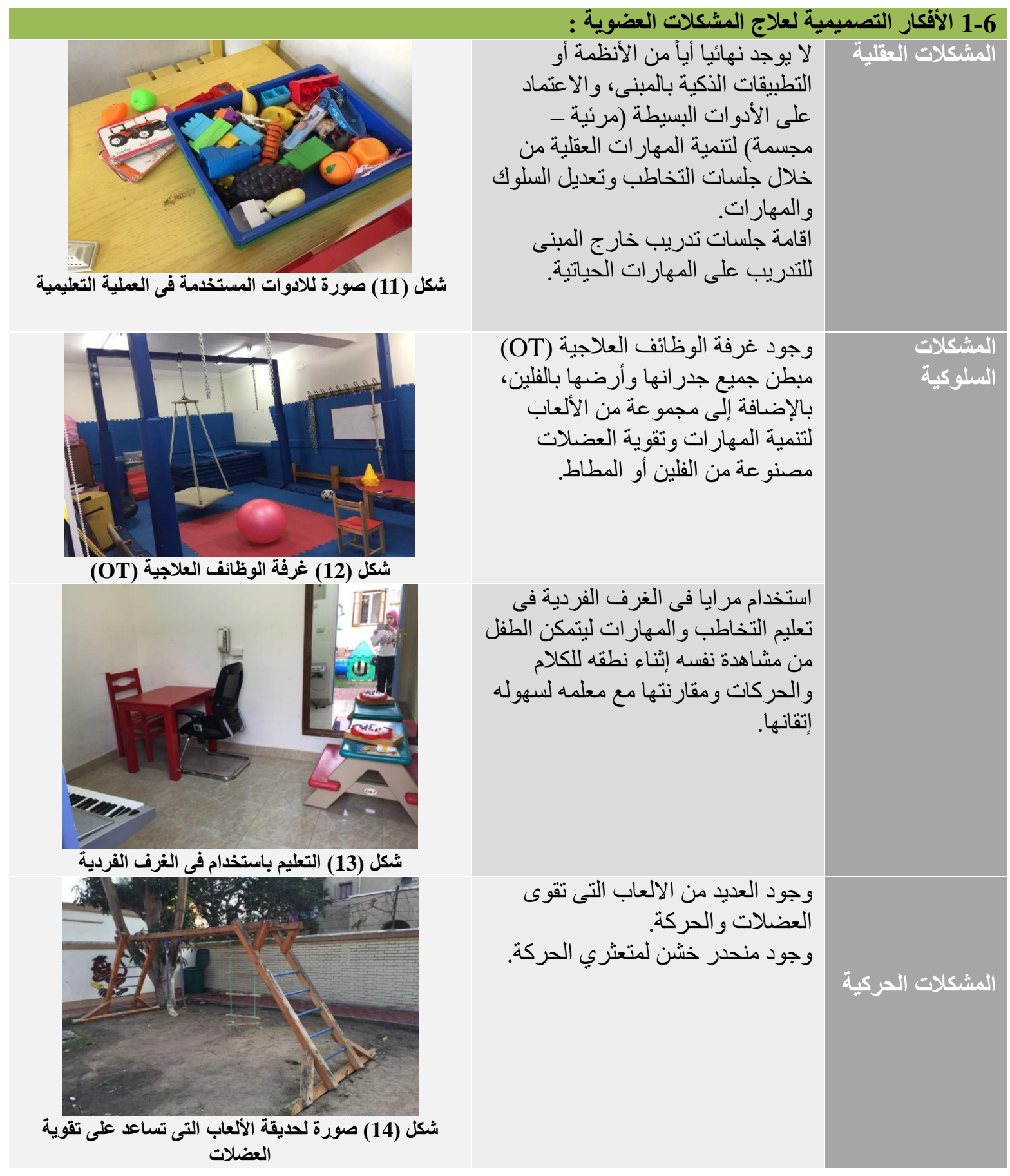



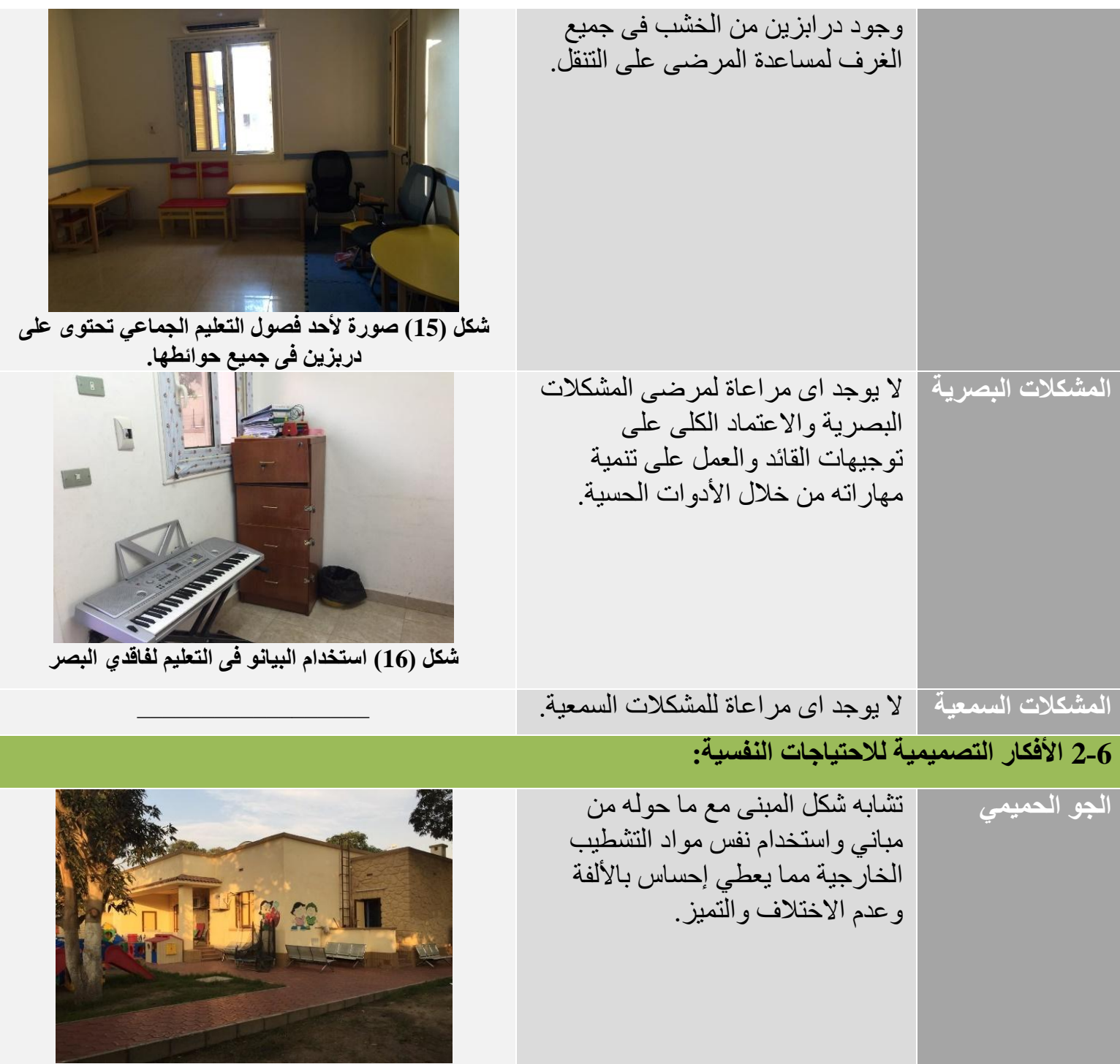

شكل (17) صورة منظورية للمبنح

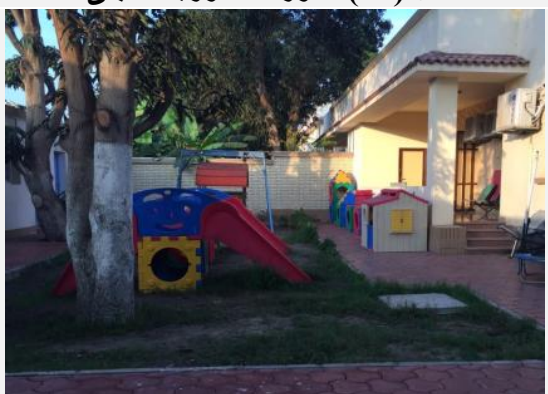

بالإضافة لتو افر مناطق خضر اء.

شكل (18) الحديقة التعليمية بالمركز

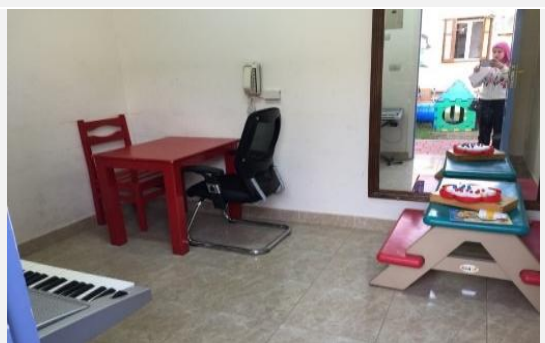

شكل (19) صورة لإحدى الفصول الفردية one to one

الأخذ في الاعتبار اللعب الذي يعد احد

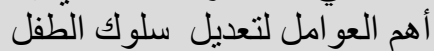
المعوق ذهنياً. 


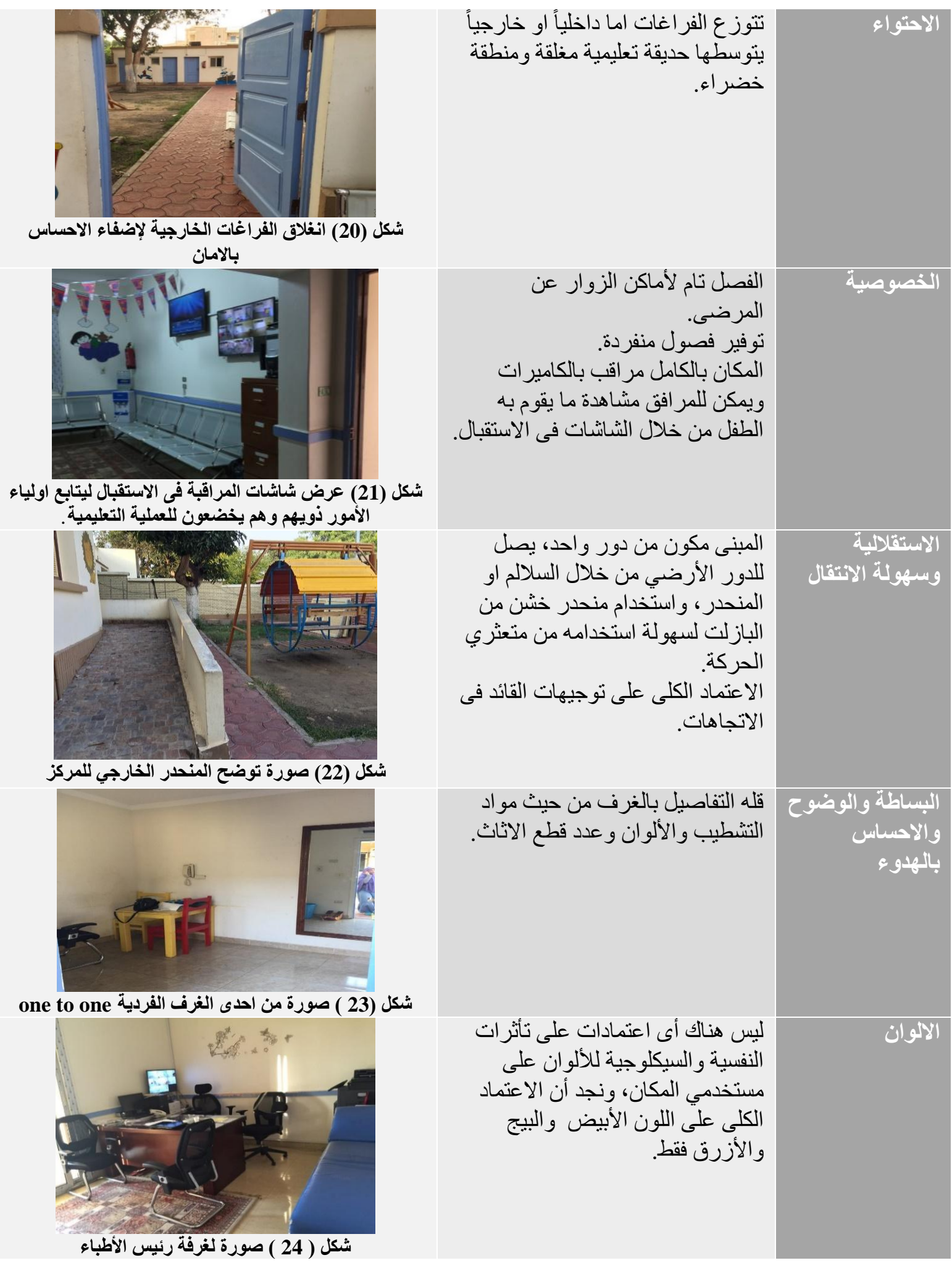




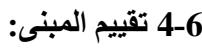

\begin{tabular}{|c|c|c|c|}
\hline لا تمثقى & 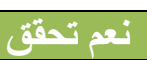 & & الاعبارات الأعضوية \\
\hline$\bullet$ & 0 & استخدام الانظمة الذكية & المشكلات العقلية \\
\hline$\bullet$ & O & الاسقف و الارضيات & \multirow{5}{*}{ المشكلات السلوكية } \\
\hline 0 & $\bullet$ & الاعمدة & \\
\hline$\bullet$ & 0 & الحوائط & \\
\hline 0 & $\bullet$ & الأمن و الأمان & \\
\hline 0 & $\bullet$ & الاثاث & \\
\hline 0 & $\bullet$ & الممرات & \multirow{6}{*}{ المشكلات الحركية } \\
\hline$\bullet$ & 0 & الابو اب & \\
\hline o & $\bullet$ & النو افذ & \\
\hline 0 & $\bullet$ & السلالم و المنحدر ات و الرو افع الكهربية & \\
\hline 0 & $\bullet$ & الحمامات & \\
\hline$\bullet$ & O & الفرش و الاثاث & \\
\hline$\bullet$ & 0 & السلالم & \multirow{4}{*}{ المشكلات البصرية } \\
\hline$\bullet$ & 0 & التوجيه & \\
\hline$\bullet$ & $\mathrm{O}$ & الإضناءه & \\
\hline 0 & $\bullet$ & الامتداد البصري & \\
\hline$\bullet$ & 0 & عزل الضوضناء & المشكلات السمعية \\
\hline & & & 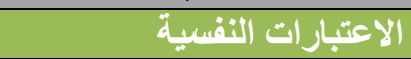 \\
\hline 0 & $\bullet$ & الشكل التصميمى للمبنى & \multirow{4}{*}{ الجو الحميمي } \\
\hline 0 & $\bullet$ & الظلال بالمبنى . & \\
\hline 0 & $\bullet$ & درجة الحر ارة بالمبنى & \\
\hline 0 & $\bullet$ & العناصر الطبيعية & \\
\hline 0 & $\bullet$ & النسب و المقاييس & \multirow[t]{2}{*}{ الاحتو اء } \\
\hline 0 & $\bullet$ & درجة الانغلاق & \\
\hline$\bullet$ & 0 & التقسيم الداخلى للفر اغات & الخصوصية \\
\hline$\bullet$ & $\circ$ & التوجيه & \multirow[t]{3}{*}{ الاستقلالية وسهولة الإنتقال } \\
\hline 0 & $\bullet$ & الحركة الافقية & \\
\hline 0 & $\bullet$ & الحركة الر أسية & \\
\hline 0 & $\bullet$ & التشطيب الداخلى & \multirow{2}{*}{ بالهدوء البساطة والوضوح و الاحساس } \\
\hline 0 & $\bullet$ & توزيع الفر اغات & \\
\hline$\bullet$ & 0 & تأثثير ات الالوان & الالوان \\
\hline \multicolumn{4}{|r|}{ 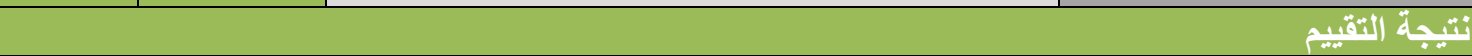 } \\
\hline & 18 & 30 & المجموع الكلي \\
\hline
\end{tabular}

مدى توافث المبنى مع الإحتياجات النفسية

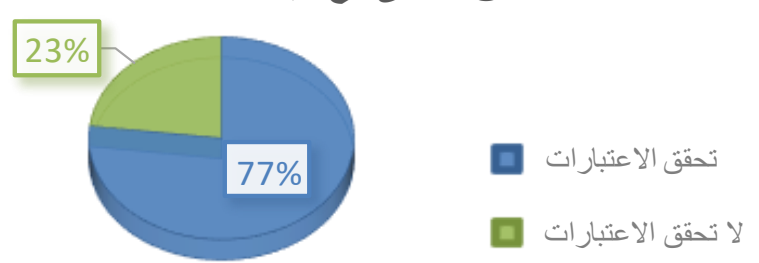

شكل ( 26 ) مدى توافق المبني مع الاحتياجات النفسية
مدى تو افقى المبنى مع المشكلات العضوية

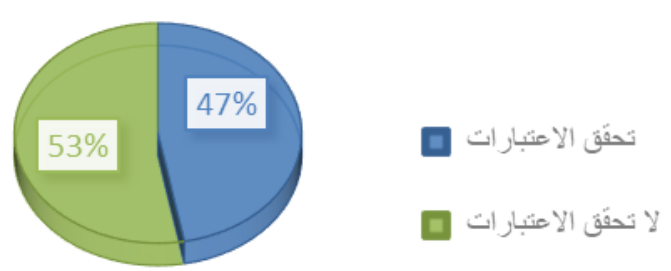

شكل (25 ) مدى توافق المبني مع المشكلات العضوية 


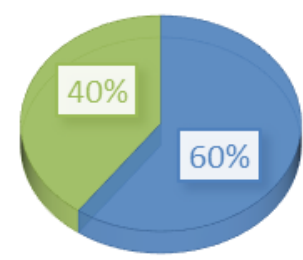

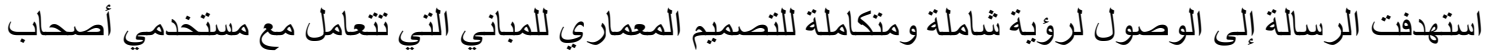

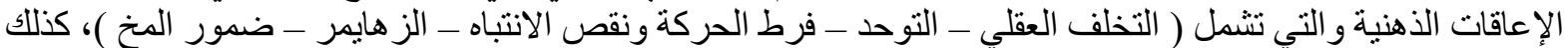

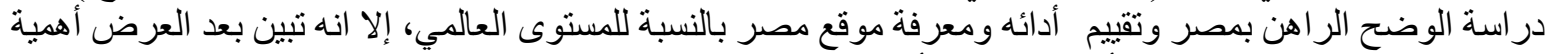

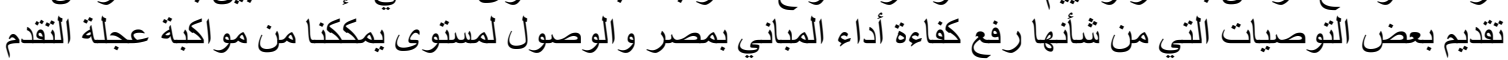

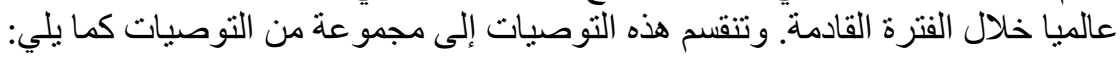

أولاً: توصيات علي مستوي المعماريين والمنفذين:

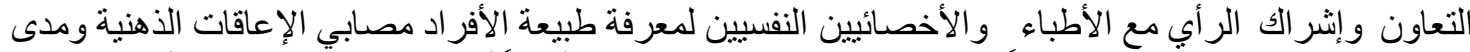

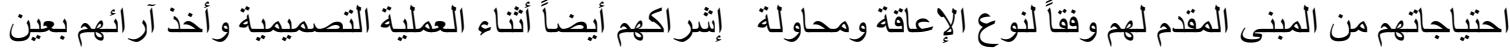
الاعتبار للخروج بتصميم ير اعي الاعتبارات التصميمية الطبية و النفسية والمعية التعمارية.

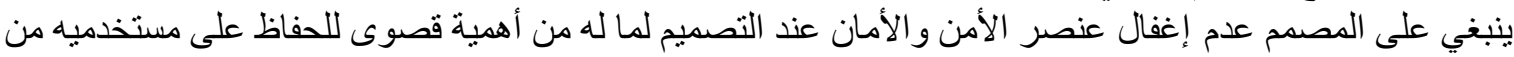

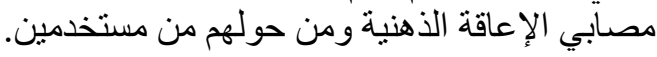

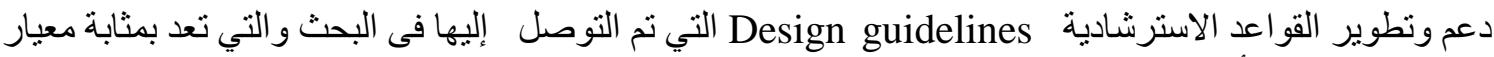

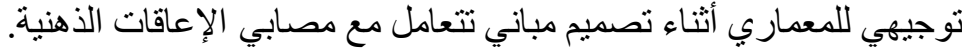

محاولة الاستفادة من التجارب العالمية والأبحاث العلمية الخاصة بمثل هذه النوعية من المباني قبل البداء في إعداد تصميماته.

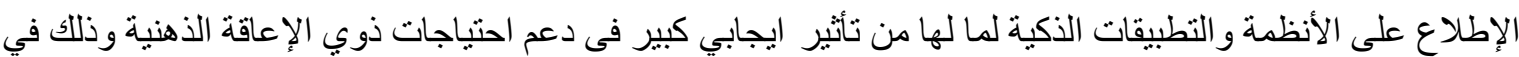

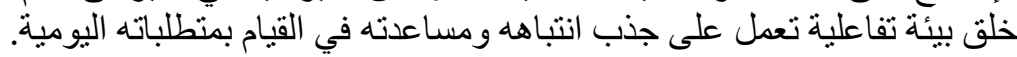

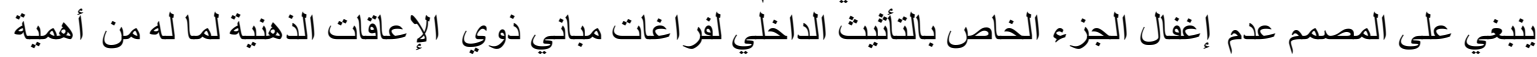
كبرى فى النظام الإداري و الوظيفي داخل المبنى.

\section{ثانياً: توصيات علي مستوي الاولة:}

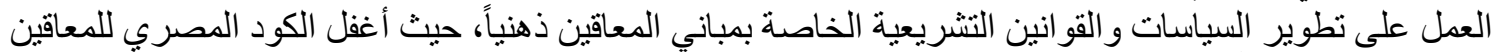

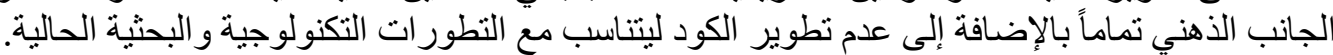

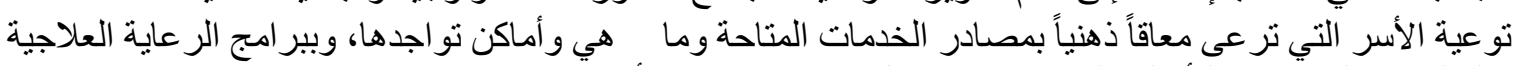

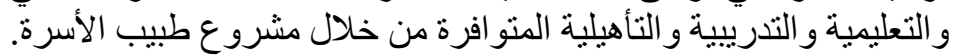

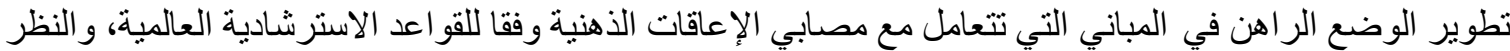

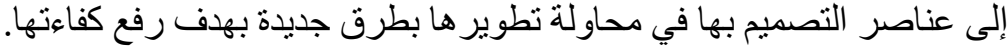

ثالثاً: توصيات علي المستوي التعليمي والأكاديمي:

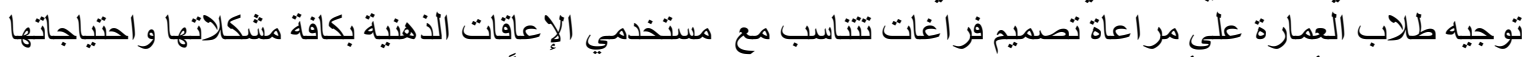

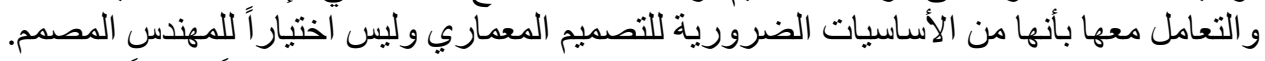

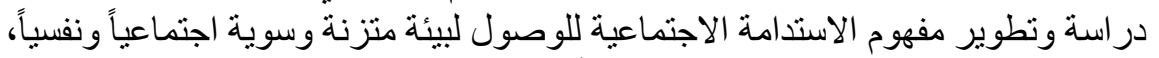

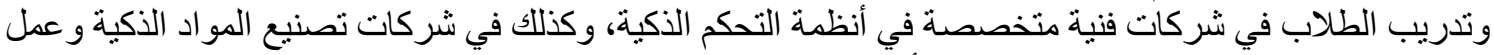
محاضرات وندو ات تحت إدارة مشتركة بين أقسام العمارة وتلك الثرة الثركات. 
رابعاً: توصيات في مجال الأبحاث والدراسات المستقبلية:

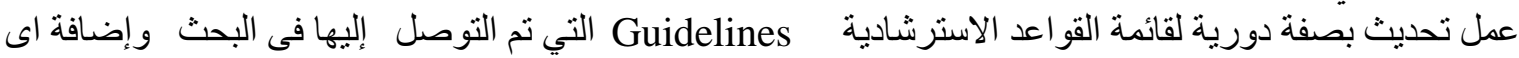

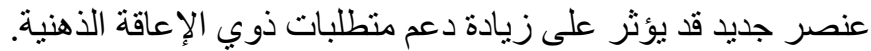

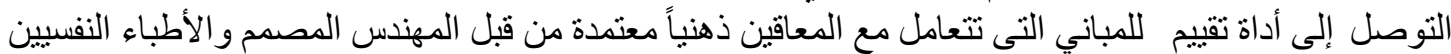

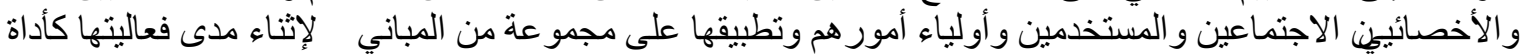

للتقبيم.

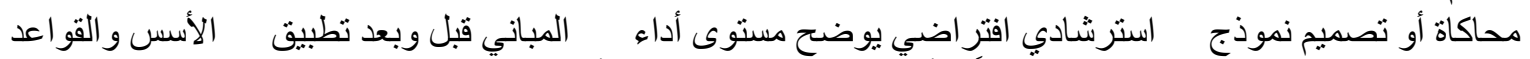
الاسترشادية الخاصة بمباني المعاقين ذهنياً وتأثير ذلك على المستوى الأدائي لمستخدميه ودرجة تقبل فيلهم للمبنى وتفاعلهم

\section{المراجع العربية}

1. قدو، ياسر تحمح سعيد ، (2018)، أثر الحالات النفسية في قضايا الأحوال الثخصية، المركز العربي للار اسات

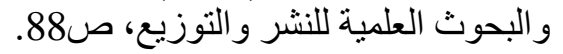

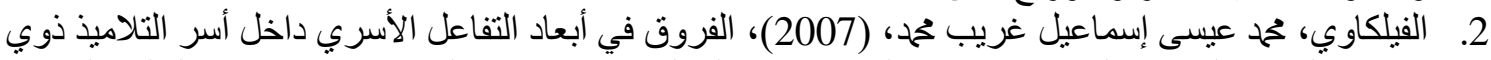

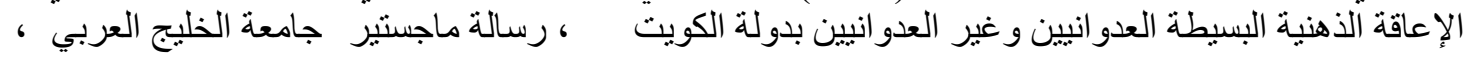

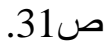

3 الجندي، آلاء أكرم ححمد ، (2014)، أسس تصميم البيئة التعليمية الخاصة بالأطفال المصابين بالتوحد ماجستير

4. السلنتي، رشا محمد حسين، (2011)، معايير تصميمية وتكنولوجية للتصميم الداخلي و الأثاث لمر اكز الطب النفسي،

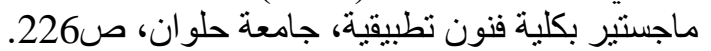

5. سمرة، هبة عبد الحفيظ، (2008)، العمارة الداخلية لدور رعاية صلية المعاقين ذهنيا، ماجستير الفنون الجميلة ، جامعة

6. الجندي، آلاء أكرم محمد ، (2014)، أسس تصميم البيئة التعليمية الخاصة بالأطفال المصابين بالتوحد ماجستير

6. - الجندي، آلاء أكرم.

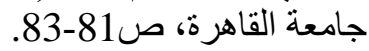

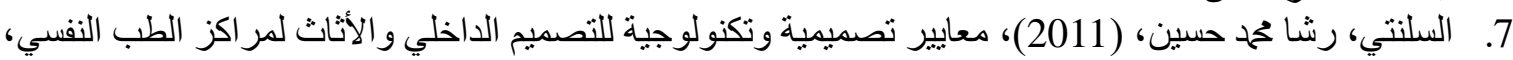

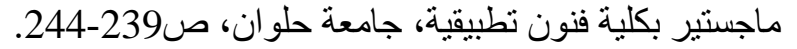

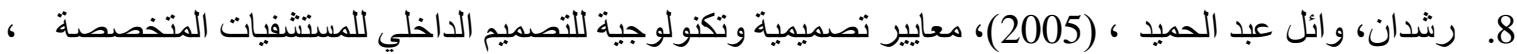

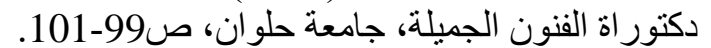

9. علي، ريهام عبد المنعم السيد، (2011)، تصميم العمارة الداخلية لمرضى التوحد، دكتور اه الفنون الجميلة، جامعة

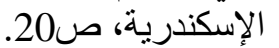

10. عبد المنعم ، أحمد رمضانة ، الإندان (2012)، رصد وتحليل دور المسنين ومعايير تصميمها وفقاً لر احة المقيمين بها

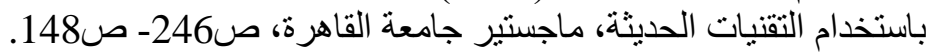

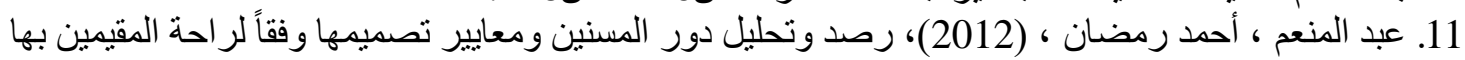

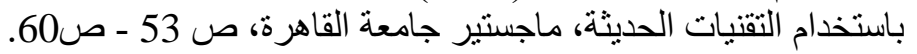

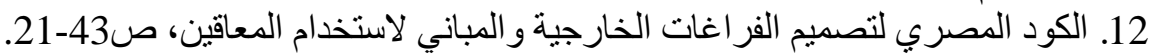

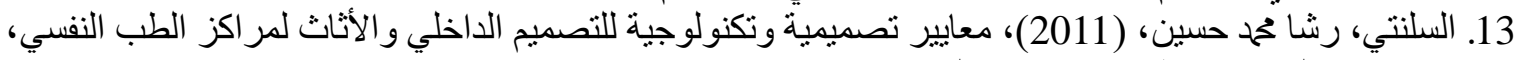

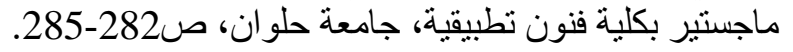

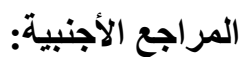

1. Tasha, Stanly, (March14,2015), A beautiful mind: history of the treatment of mental illness, published in history cooperative - a short history of nearly everything.

2. Lauren, Hoopes, (May 2015), on the periphery: a survey if nineteenth century asylums in the united states.

3. Department of veterans affairs, office of construction \& facilities management, (December 2010), Mental Health Facilities D esign Guide. 